\title{
Genetic linkage to the type VII collagen gene (COL7A1) in 26 families with generalised recessive dystrophic epidermolysis bullosa and anchoring fibril abnormalities
}

\author{
M G S Dunnill, A J Richards, G Milana, F Mollica, D Atherton, I Winship, \\ M Farrall, L Al-Imara, R A J Eady, F M Pope
}

MRC Clinical

Research Centre,

Northwick Park

Hospital,

Middlesex, UK

M G S Dunnill

A J Richards

L Al-Imara

F M Pope

St John's Institute of Dermatology,

St Thomas's Hospital, Lambeth Palace Road, London SE1 7EH, UK M G S Dunnill

R A J Eady

Clinica Pediatrica, Universita di Catania, Sicily, Italy

G Milana

F Mollica

The Hospital for Sick Children, Great Ormond Street, London

D Atherton

Departments of Dermatology and Human Genetics, University of Cape Town, Cape Town, South Africa

I Winship

RPMS, Hammersmith Hospital, London, UK M Farrall

Correspondence to Dr Dunnill.

Received 18 March 1994 Revised version accepted for publication 23 May 1994

\begin{abstract}
To strengthen the evidence for genetic linkage to COL7A1, we have studied 26 generalised recessive dystrophic epidermolysis bullosa (EB) families of British, Italian, Irish, and South African origin. We chose two linkage markers, a COL7A1 PvuII intragenic polymorphism and a highly informative anonymous microsatellite marker, D3S1100, which maps close to the COL7A1 locus at 3p21.1-3. Diagnosis was established by family history, clinical examination, immunofluorescence, and ultrastructural studies. The PvuII marker was informative in 16 families with a maximum lod score ( $\mathrm{Zmax}$ ) of 3.51 at recombination fraction $(\theta)=0$. The D3S1100 microsatellite was informative in 24 out of 25 families with $Z \max =6.8$ at $\theta=0.05(Z=4.94$ at $\theta=0)$ and no obligatory recombination events. These data strongly suggest that COL7A1 mutations cause $E B$ in these families and, combined with previous studies, indicate locus homogeneity. The importance of anchoring fibrils for dermal-epidermal adhesion is further underlined. D3S1100 may later prove useful in prenatal diagnosis of this disease, if used in combination with other markers.
\end{abstract}

\section{(于 Med Genet 1994;31:745-748)}

Epidermolysis bullosa (EB) encompasses a group of inherited diseases characterised by inappropriate blistering of the skin after minor trauma. Clinically it varies from a limited, nonscarring form to a severe mutilating disorder with widespread loss of skin and scarring. Three major types are separated on the basis of the microscopic level of blistering within the skin ${ }^{1}$ : (1) EB simplex with cleavage through the basal epidermis; (2) junctional EB with cleavage through the lamina lucida of the basement membrane; and (3) dystrophic EB with cleavage below the lamina densa of the basement membrane. Dystrophic EB has autosomal dominant and recessive forms. Attempts at further sub-categorisation ${ }^{2}$ have been based on both clinical and microscopic variation in the phenotype, but there is overlap between categories causing difficulties in precise classification.

COL7A1 is the prime candidate gene for both autosomal dominant and recessive dystrophic EB. Anchoring fibrils, visible on electron microscopy as cross banded fanning structures extending from the lower lamina densa into the papillary dermis, are composed mainly of type VII collagen ${ }^{3}$ and have both qualitative and quantitive abnormalities in dystrophic EB. ${ }^{45}$ In generalised recessive dystrophic EB, recognisable anchoring fibrils may be missing and immunofluorescence staining with type VII collagen antibodies is markedly reduced or absent. ${ }^{6-8}$ Partial cloning of COL7A $1^{9}$ and identification of an intragenic PvuII polymorphism ${ }^{10}$ enabled demonstration of tight linkage to dominant dystrophic $\mathrm{EB}^{10-13}$ and, in one study of 19 patients from France, to generalised recessive dystrophic EB with $\mathrm{Zmax}=3.97$ at $\theta=0 .{ }^{14}$ Recently a homozygous insertion-deletion within the N-terminal noncollagenous (NC1) domain of COL7A1 has been recognised in a generalised recessive dystrophic EB patient ${ }^{15}$ and a methionine to lysine substitution within the C-terminal non-collagenous (NC2) domain of a patient with mitis type of recessive dystrophic EB. ${ }^{16}$ These data strongly suggest that COL7A1 mutations cause EB in these patients. Following the demonstration of increased synthesis and secretion of collagenase ${ }^{1718}$ the collagenase genes became strong candidates. However, two independent studies have excluded genetic linkage between it and recessive dystrophic EB. ${ }^{1920}$

Informative markers which are tightly linked to a disease locus can be used for prenatal diagnostic testing of fetal DNA obtained from chorionic villus samples at 11 weeks' gestation. ${ }^{21}$ Currently prenatal diagnosis of EB is performed by electron microscopy and immunofluorescence of a fetal skin biopsy, taken at 16 weeks' gestation. ${ }^{22}$ Although there have been reports of prenatal diagnosis with the PruII RFLP, ${ }^{2324}$ this marker is only fully 
informative in some cases (heterozygosity in our population was $36 \%$ ). A highly informative marker would therefore be very useful for this purpose.

We have tested linkage to COL7A1 in 26 further generalised recessive dystrophic EB families to confirm the previous study and to seek evidence of locus heterogeneity. We chose the intragenic PvuII COL7A1 RFLP and a second, microsatellite repeat marker, D3S $1100 .{ }^{25}$ This marker has a heterozygosity of $77 \%$ and has been mapped close to $3 \mathrm{p} 21.3$ by the NIH/CEPH collaborative mapping group. ${ }^{26}$ We have also examined the suitability of this marker for prenatal diagnosis by its segregation patterns in our families.

\begin{abstract}
Materials and methods
PATIENTS

Families with generalised recessive dystrophic EB were recruited from clinics in London at St Thomas's Hospital, Great Ormond Street Hospital, and through the three charitable organisations, DEBRA UK, DEBRA Ireland, and DEBRA Italy. One family was also included from South Africa. Clinical details were catalogued and a skin biopsy, taken from unblistered skin after gentle rubbing, was examined by transmission electron microscopy using standard methods. ${ }^{27}$ Indirect immunofluorescence using LH7:2, ${ }^{28} \mathrm{~GB} 3,{ }^{29}$ and anti-type IV collagen antibodies was performed on UK patients. Blood samples were taken from all available family members with ethical committee approval.
\end{abstract}

DNA ANALYSIS

Standard methods were used for phenol/chloroform extraction of lymphocyte genomic DNA. Two variable DNA markers were used. (1) PvuII RFLP. The PCR was used to amplify a $431 \mathrm{bp}$ fragment containing the relevant PvuII site. (Primer 1: 5'GTGGCCAGGAACAGTCCCGGGTCC3'; primer 2: 5'CGAGGTGTCCACCACACGTAGTTC3'). After five minutes denaturing at $95^{\circ} \mathrm{C}, 30$ cycles of denaturing at $95^{\circ} \mathrm{C}$, annealing at $68^{\circ} \mathrm{C}$ and elongation at $72^{\circ} \mathrm{C}$ were performed. Amplified fragments were digested with PvuII (Northumbria Biologicals Limited) and separated on $2 \%$ agarose gels (fig 1A). (2) D3S1100 microsatellite. PCR amplification of this microsatellite using ${ }^{32} \mathrm{P}$ end labelled primer 1 (5'GGTTTCATATACCATCAATCCCAC3') and cold primer 2 (5'GTACACCATCATGAGGAGTCTGG3') was performed. ${ }^{25}$ PCR product $(10 \mu \mathrm{l})$ and $4 \mu \mathrm{l}$ of loading buffer $(98 \%$ formamide, $1 \%$ xylene cyanol, $1 \%$ bromophenol blue) were heated to $95^{\circ} \mathrm{C}$ for five minutes, cooled on ice, and the single stranded products were immediately electrophoresed on $6 \%$ polyacrylamide gels containing $8 \mathrm{~mol} / 1$ urea at $37 \mathrm{~W}$ for three to four hours. The dried gel was autoradiographed at $-70^{\circ} \mathrm{C}$ for two to seven days (fig 1B).

\section{LINKAGE ANALYSIS}

Two point lod scores were calculated using the MLINK programme in the LINKAGE package. ${ }^{30}$ Allelic frequencies were calculated on the basis of 47 unrelated persons from our study population. Autosomal recessive inheritance and complete penetrance were assumed.

\section{Results}

CLINICAL AND ULTRASTRUCTURAL FINDINGS

The structure, consanguinity, and origins of the 26 families are shown in table 1 and fig 2 . All patients had extreme skin fragility with blistering, scarring, and milia formation from birth. Nail loss, pseudosyndactyly, con-
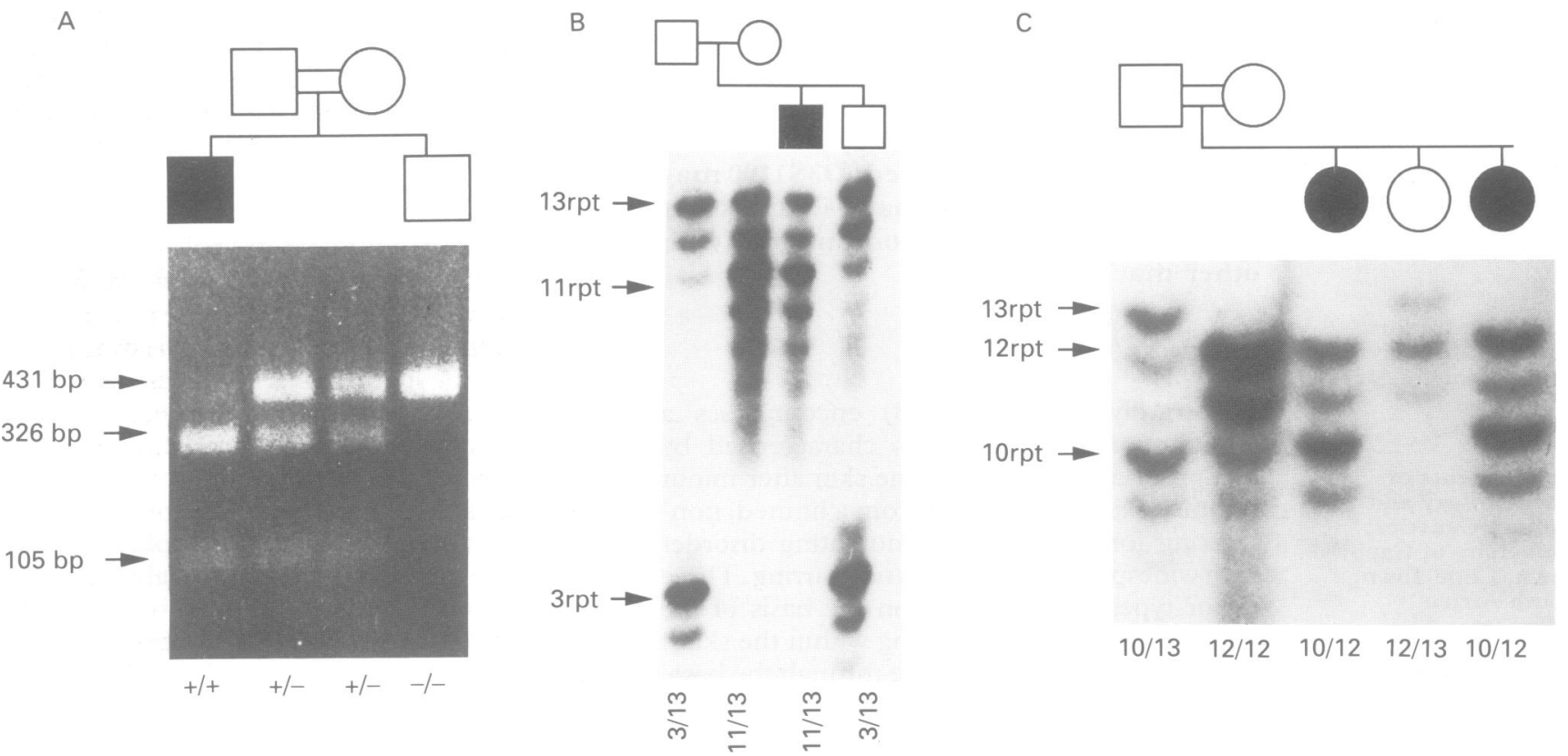

Figure 1 Marker results. Pedigrees are shown with subjects above their corresponding lane. Open box: unaffected male; open circle: unaffected female; filled box: affected male; filled circle: affected female. $(A)$ PvuII RFLP in family 13. The affected child is homozygous for the + allele and shows two digested fragments of $326 \mathrm{bp}$ and $105 \mathrm{bp}$. (B) D3S1100 microsatellite in family 12. (C) D3S1100 microsatellite in family 15. Arrows show the number of repeats (rpt). 
Table 1 Structure, consanguinity, and origin of families with generalised recessive dystrophic epidermolysis bullosa

\begin{tabular}{|c|c|c|c|c|c|}
\hline Family & Origin (race) & Consanguinity & No of parents & $\begin{array}{l}\text { No of affected } \\
\text { offspring }\end{array}$ & $\begin{array}{l}\text { Total no of } \\
\text { offspring }\end{array}$ \\
\hline 1 & UK (White) & No & 2 & 1 & 2 \\
\hline 2 & UK (White) & No & 2 & 1 & 2 \\
\hline 3 & UK (White) & No & 2 & 1 & 2 \\
\hline 4 & UK (White) & No & 2 & i & 2 \\
\hline 5 & UK (White) & No & 2 & 1 & 2 \\
\hline 6 & UK (White) & No & 2 & 1 & 2 \\
\hline 7 & UK (White) & No & 2 & 2 & 2 \\
\hline 8 & UK (White) & No & 2 & 1 & 3 \\
\hline 9 & UK (White) & No & 2 & 1 & 3 \\
\hline 10 & UK (White) & No & 2 & 1 & 4 \\
\hline 11 & UK White) & 1st degree & $4^{*}$ & 2 & 2 \\
\hline 12 & UK (African) & No & 2 & 1 & 2 \\
\hline 13 & UK (African) & 1st degree & 2 & 1 & 2 \\
\hline 14 & UK (Asian) & No & 2 & 1 & 2 \\
\hline 15 & UK (Asian) & 1st degree & 2 & 2 & 3 \\
\hline 16 & UK (Asian) & 1st degree & 2 & 1 & 6 \\
\hline 17 & Eire (White) & No & 2 & 1 & 2 \\
\hline 18 & Eire (White) & 1st degree & 2 & 2 & 3 \\
\hline 19 & Eire (White) & No & 2 & 1 & 4 \\
\hline 20 & SA (Asian) & No & 2 & 1 & 2 \\
\hline 21 & Italy (White) & No & 2 & 2 & 2 \\
\hline 22 & Italy (White) & No & 2 & 1 & 2 \\
\hline 23 & Italy (White) & No & 2 & 1 & 2 \\
\hline 24 & Italy (White) & No & 2 & 1 & 2 \\
\hline 25 & Italy (White) & 1st degree & $4^{*}$ & 2 & 2 \\
\hline 26 & Italy (White) & No & 2 & 2 & 3 \\
\hline
\end{tabular}

$\mathrm{SA}=$ South Africa. ${ }^{*}$ Pedigrees for the two families with four parents were identical (fig 2).

Table 2 Lod score table between generalised recessive dystrophic epidermolysis bullosa phenotype and (A) PvuII marker and (B) D3S1100 microsatellite

\begin{tabular}{|c|c|c|c|c|c|c|c|}
\hline \multirow{2}{*}{$\begin{array}{l}\text { (A) } \\
\text { Family }\end{array}$} & \multicolumn{7}{|c|}{ Recombination fraction $(\theta)$} \\
\hline & 0.0 & 0.01 & 0.05 & $0 \cdot 1$ & $0 \cdot 2$ & $0 \cdot 3$ & 0.4 \\
\hline 1 & -0.18 & -0.17 & -0.14 & $-0 \cdot 10$ & -0.06 & -0.02 & -0.01 \\
\hline 3 & -0.18 & -0.17 & -0.14 & -0.10 & -0.06 & -0.02 & -0.01 \\
\hline 4 & 0.12 & $0 \cdot 12$ & $0 \cdot 10$ & 0.08 & 0.05 & 0.02 & 0.01 \\
\hline 6 & 0.12 & 0.12 & $0 \cdot 10$ & 0.08 & 0.05 & 0.02 & 0.01 \\
\hline 7 & 0.3 & 0.29 & $0 \cdot 26$ & 0.21 & 0.13 & 0.06 & 0.02 \\
\hline 9 & 0.25 & $0 \cdot 24$ & $0 \cdot 21$ & $0 \cdot 17$ & $0 \cdot 10$ & 0.05 & 0.01 \\
\hline 11 & $0 \cdot 2$ & $0 \cdot 19$ & $0 \cdot 14$ & 0.08 & 0.01 & -0.02 & -0.01 \\
\hline 13 & $0 \cdot 24$ & 0.23 & $0 \cdot 18$ & $0 \cdot 13$ & 0.05 & 0.01 & -0.01 \\
\hline 15 & $0 \cdot 10$ & $0 \cdot 10$ & 0.08 & 0.06 & 0.03 & 0.01 & 0.00 \\
\hline 16 & 0.5 & 0.49 & 0.43 & $0 \cdot 37$ & $0 \cdot 24$ & $0 \cdot 13$ & 0.05 \\
\hline 18 & 0.84 & 0.82 & 0.71 & 0.58 & 0.33 & 0.13 & 0.01 \\
\hline 20 & 0.12 & $0 \cdot 12$ & $0 \cdot 10$ & 0.08 & 0.05 & 0.02 & 0.01 \\
\hline 22 & $0 \cdot 12$ & 0.12 & $0 \cdot 10$ & 0.08 & 0.05 & 0.02 & 0.01 \\
\hline 23 & $0 \cdot 12$ & 0.12 & $0 \cdot 10$ & 0.08 & 0.05 & 0.02 & 0.01 \\
\hline 25 & 0.67 & 0.65 & 0.55 & $0 \cdot 44$ & $0 \cdot 25$ & $0 \cdot 11$ & 0.04 \\
\hline 26 & $0 \cdot 12$ & 0.12 & 0.09 & 0.06 & 0.02 & 0.00 & 0.00 \\
\hline Total & 3.51 & 3.38 & $2 \cdot 89$ & $2 \cdot 3$ & $1 \cdot 3$ & 0.56 & 0.13 \\
\hline
\end{tabular}

\begin{tabular}{|c|c|c|c|c|c|c|c|}
\hline \multirow{2}{*}{$\begin{array}{l}\text { (B) } \\
\text { Family }\end{array}$} & \multicolumn{7}{|c|}{ Recombination fraction } \\
\hline & 0.0 & 0.01 & 0.05 & $0 \cdot 1$ & $0 \cdot 2$ & $0 \cdot 3$ & 0.4 \\
\hline 2 & 0.12 & $0 \cdot 12$ & 0.09 & 0.06 & 0.02 & 0.00 & 0.00 \\
\hline 3 & 0.12 & 0.12 & 0.09 & 0.06 & 0.02 & 0.00 & 0.00 \\
\hline 4 & 0.12 & 0.12 & $0 \cdot 10$ & 0.08 & 0.05 & 0.02 & 0.01 \\
\hline 5 & 0.12 & 0.12 & 0.09 & 0.06 & 0.02 & 0.00 & 0.00 \\
\hline 6 & 0.12 & 0.12 & 0.09 & 0.06 & 0.02 & 0.00 & 0.00 \\
\hline 7 & 0.60 & 0.58 & 0.52 & 0.43 & $0 \cdot 27$ & $-0 \cdot 13$ & 0.03 \\
\hline 8 & 0.25 & $0 \cdot 24$ & $0 \cdot 19$ & $0 \cdot 14$ & 0.06 & 0.02 & 0.00 \\
\hline 9 & -0.05 & -0.05 & -0.04 & -0.03 & -0.02 & -0.01 & 0.00 \\
\hline 10 & 0.37 & 0.36 & 0.29 & 0.22 & 0.12 & 0.05 & 0.01 \\
\hline 11 & $1 \cdot 33$ & $1 \cdot 30$ & $1 \cdot 16$ & 1.00 & 0.66 & 0.36 & $0 \cdot 12$ \\
\hline 12 & 0.12 & 0.12 & 0.12 & $0 \cdot 11$ & 0.08 & 0.04 & 0.01 \\
\hline 13 & 0.59 & 0.57 & 0.50 & 0.41 & 0.25 & 0.13 & 0.05 \\
\hline 14 & 0.12 & 0.12 & 0.09 & 0.06 & 0.02 & 0.00 & 0.00 \\
\hline 15 & -1.48 & -0.78 & -0.23 & -0.03 & 0.07 & 0.05 & 0.02 \\
\hline 16 & 1.30 & $1 \cdot 27$ & $1 \cdot 16$ & 1.02 & 0.73 & 0.44 & 0.18 \\
\hline 17 & 0.12 & 0.12 & 0.09 & 0.06 & 0.02 & 0.00 & 0.00 \\
\hline 18 & 1.59 & 1.55 & 1.42 & $1 \cdot 25$ & 0.89 & 0.55 & 0.24 \\
\hline 19 & 0.37 & 0.37 & 0.33 & $0 \cdot 28$ & $0 \cdot 19$ & $0 \cdot 10$ & 0.03 \\
\hline 20 & 0.12 & 0.12 & $0 \cdot 12$ & $0 \cdot 11$ & 0.08 & 0.04 & 0.01 \\
\hline 21 & 0.6 & 0.58 & 0.52 & 0.43 & 0.27 & 0.13 & 0.03 \\
\hline 22 & 0.12 & 0.12 & 0.12 & 0.11 & 0.08 & 0.04 & 0.01 \\
\hline 23 & $0 \cdot 12$ & $0 \cdot 12$ & 0.12 & 0.11 & 0.08 & 0.04 & 0.01 \\
\hline 24 & $0 \cdot 12$ & $0 \cdot 12$ & 0.09 & 0.06 & $0 \cdot 02$ & 0.00 & 0.00 \\
\hline 25 & -2.03 & -0.79 & -0.20 & -0.02 & 0.06 & 0.04 & 0.01 \\
\hline Total & 4.94 & $6 \cdot 64$ & $6 \cdot 8$ & 6.01 & $4 \cdot 04$ & $2 \cdot 2$ & 0.78 \\
\hline
\end{tabular}

tractures, and oesophageal strictures developed in older children. Electron microscopy confirmed the structural and numerical abnormality of anchoring fibrils, with a level of

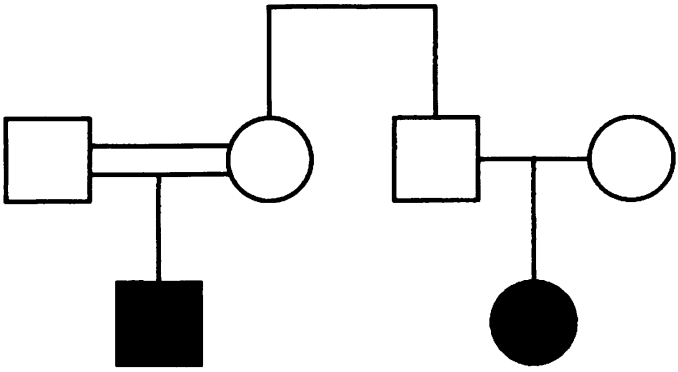

Figure 2 The pedigree structure for families 11 and 25. Double line indicates consanguineous marriage.

cleavage, if present, below the lamina densa. Immunofluorescence in UK patients showed no visible staining with $\mathrm{LH} 7: 2$ antibody except in a few cases where staining was present although greatly reduced in intensity and in a patchy distribution compared to controls. GB3 and type IV collagen staining were consistently normal.

DNA ANALYSIS AND LINKAGE

The lod scores for the PvuII RFLP and the microsatellite marker are shown in table 2(A) and (B) respectively. All families were informative for at least one of the markers. The 16 informative families for the PvuII RFLP gave a combined maximum lod score of 3.51 at $\theta=0$ with no obligatory recombinations. Our observed allelic frequencies were 0.28 ( + allele) and 0.72 ( - allele). Heterozygosity in 50 unrelated persons was $36 \%$. Zmax for the microsatellite was 6.8 at $\theta=0.05$ with $Z=4.94$ at $\theta=0$. Although there were no obligatory recombinations, in two consanguineous families (15 and 25) the affected patients were heterozygous for the marker, suggesting a probable recombination event in the grandparents or great grandparents (fig 1C). The calculated two point lod score between the two markers estimates the proximity of D3S1100 to COL7Al (full lod table not shown). Thirteen families were informative for both markers with 28 informative meioses and one obligatory recombination. The disease showed no clustering of any particular allele for either marker.

\section{Discussion}

The lod score of 3.52 for the PvuII RFLP in our generalised recessive dystrophic EB families is highly significant and confirms the results of Hovnanian et al. ${ }^{14}$ The PruII polymorphism lies in the coding sequence for a fibronectinlike domain (FN-8) in the NC-1 region of the type VII collagen molecule. ${ }^{91431}$ The combined evidence of positive gene linkage, abnormalities of anchoring fibrils and type VII collagen protein expression in epidermal basement membrane, and the observation of two recessive dystrophic EB patients with separate COL7A1 mutations ${ }^{1516}$ strongly suggests that all generalised recessive dystrophic EB families have allelic mutations.

Since the PvuII marker was only informative in 16 out of 26 families we used the microsatellite repeat $\mathrm{D} 3 \mathrm{~S} 1100$ at $3 \mathrm{p} 21.1-3 .^{92632}$ This was informative for 24 out of 25 families tested. There were two possible recombinations 
(consanguineous families 15 and 25) probably occurring in the grandparents or great grandparents with consequent heterozygosity in affected children. Alternatively, but less likely, the children are compound heterozygotes for mutations in COL7A1. Both families gave positive lod scores with the PvuII RFLP. Zmax for the microsatellite marker was at $\theta=0.05$. Linkage analysis between the microsatellite and PvuII marker site showed only one recombination in 28 informative meioses. These observations, combined with NIH/CEPH collaborative mapping group data, ${ }^{26}$ suggest a maximum distance of $5 \mathrm{cM}$ between COL7A1 and D3S1100. If used alone for prenatal diagnosis this predicts a $5 \%$ recombination (misdiagnosis) rate which we consider unacceptably high. However, in combination with a second suitable microsatellite located at the opposite flank of COL7A1, it could form the basis of an accurate and informative test for the majority of families.

Other workers have tested the hypothesis that the collagenase gene participates in the pathogenesis of recessive dystrophic EB, but two independent reports have excluded gene linkage. ${ }^{1920}$

Finally, despite strict criteria for clinical selection, we have noted significant interfamilial variation of clinical severity. Very probably this is related to the site and type of mutation within COL7A1. The lack of linkage disequilibrium for particular RFLP genotypes supports the hypothesis that many different COL7A1 mutations produce the EB clinical phenotype and is consistent with observations of other diseases such as osteogenesis imperfecta, Ehlers-Danlos syndrome type IV, and certain chondrodysplasias.

We would like to acknowledge P Dopping-Heppenstal for technical help, J A McGrath for technical and clinical support, DEBRA UK, DEBRA Italy, DEBRA Ireland, F Steinke, B J Mayou, and J Carrera for their help in recruiting patients, Alain Hovnanian for his kind advice, and all of the patients and their families who gave samples for the study. We thank DEBRA UK and the MRC for partial funding of laboratory work. MGSD is supported by a DEBRA fellowship.

1 Eady RAJ. Classification of epidermolysis bullosa. In: Priestley GC, Tidman MJ, Weiss JB, Eady RAJ, eds. Epidermolysis bullosa. A comprehensive review of classification, management and laboratory studies. Crowthorne, Berkshire: management and laborat

2 Fine JD, Bauer A, Briggaman RA, et al. Revised clinical and laboratory criteria for subtypes of inherited epidermolysis bullosa. f Am Acad Dermatol 1991;24:119-35.

3 Sakai LY, Keene DR, Morris MP, Burgeson RE. Type VII collagen is a major structural component of anchoring fibrils. F Cell Biol 1986;103:1577-86.

4 Briggaman RA, Wheeler CE. Epidermolysis bullosa dystrophica-recessive: a possible role of anchoring fibrils in the pathogenesis. F Invest Dermatol 1975;65:203-11.

5 Tidman MJ, Eady RAJ. Evaluation of anchoring fibrils and other components of the dermal-epidermal junction in dystrophic epidermolysis bullosa by a quantitive ultrastructural technique. $\mathcal{F}$ Invest Dermatol 1985;84:374-7.

6 Heagerty AHM, Kennedy AR, Leigh IM, Purkis P, Eady RAJ. Identification of an epidermal basement membrane defect in recessive dystrophic epidermolysis bullosa by tol 1986;115:125-31.

7 Bruckner-Tuderman L, Ruegger S, Odermatt B, Mitsuhashi Y, Schnyder UN. Lack of type VII collagen in unaffected skin of patients with severe recessive dystrophic episkin of patients with severe recessive dystrophic
dermolysis bullosa. Dermatologica 1988;176:57-64.

8 Leigh IM, Eady RAJ, Heagerty AHM, Purkis PE, Whitehead $\mathrm{PA}$, Burgeson E. Type VII collagen is a normal component PA, Burgeson E. Type VII collagen is a normal component expression in recessive dystrophic epidermolysis bullosa. f Invest Dermatol 1988;90:639-42.

9 Parente MG, Chung LC, Ryynanen J, et al. Human type VII collagen: cDNA cloning and chromosomal mapping of the gene. Proc Natl Acad Sci USA 1991;88:6931-5.

10 Ryynanen M, Knowlton RG, Parente MG, Chung LC, Chu $M L$, Uitto J. Human type VII collagen: genetic linkage of the gene (COL7A1) on chromosome 3 to dominan dystrophic epidermolysis bullosa. Am $\mathcal{F}$ Hum Genet 1991;

11 Ryynanen M, Ryynanen J, Sollberg S, Iozzo RV, Knowlton RG, Uitto J. Genetic linkage of type VII collagen (COL7A1) to dominant dystrophic epidermolysis bullosa in families with abnormal anchoring fibrils. $\mathcal{F}$ Clin Invest 1992;89:974-80.

12 Gruis NA, Bouwes Bavinck JN, Steiilen PM, et al. Genetic linkage between the collagen VII (COL7A1) gene and the autosomal dominant form of dystrophic epidermolysis bullosa in two Dutch kindreds. F Invest Dermatol 1992; bullosa in

13 Al-Imara L, Richards AJ, Eady RAJ, Leigh IM, Farrall M, Pope FM. Linkage of autosomal dominant dystrophic epidermolysis bullosa in three British families to the marke D3S2 close to the COL7A1 locus. I Med Genet 1992;29. 381-2.

14 Hovnanian A, Duquesnoy P, Blanchet-Bardon C, et al. Genetic linkage of recessive dystrophic epidermolysis bullosa to the type VII collagen gene. $\mathcal{F}$ Clin Invest 1992;90: 1032-6.

15 Hilal L, Rochat A, Duquesnoy P, et al. A homozygous insertion-deletion in the type VII collagen gene (COL7A1) in Hallopeau-Siemens dystrophic epidermolysis bullosa. Nature Genet 1993;5:287-93.

16 Christiano AM, Greenspan DS, Hoffman GG, et al. A missense mutation in type VII collagen in two affected siblings with recessive dystrophic epidermolysis bullosa. Nature Genet 1993;4:62-6.

17 Bauer EA, Eisen AZ. Recessive dystrophic epidermolysis bullosa: evidence for increased collagenase as a genetic bullosa: evidence for increased collagenase as a genetic
characteristic in cell culture. $₹$ Exp Med $1978 ; 148: 1378-$ 87.

18 Stricklin PG, Welgus HG, Bauer EA. Human skin collagenase in recessive dystrophic epidermolysis bullosa: purification of a mutant enzyme from fibroblast cultures. f Clin Invest 1982;69:1373-83.

19 Hovnanian A, Duquesnoy P, Amselem S, et al. Exclusion of linkage between the collagenase gene and generalized recessive dystrophic epidermolysis bullosa phenotype. $\mathcal{f}$ Clin Invest 1991;88:1716-21.

20 Colombe M, Gardella R, Zoppi N, et al. Exclusion of stromelysin-1, stromelysin-2, interstitial collagenase and fibronectin genes as the mutant loci in a family with recessive epidermolysis bullosa dystrophica and a form of cerebellar ataxia. Hum Genet 1992;89:503-7.

21 Kogan SC, Doherty M, Gitschier J. An improved method for prenatal diagnosis of genetic diseases by analysis of amplified DNA sequences. $N$ Engl f Med 1987;317:98590 .

22 Eady RAJ, Holbrook KA, Blanchet-Bardon C, Anton-Lamprecht I. Chair's summary: prenatal diagnosis of skin precht 1. Chair's summary: prenatal diagnosis of skin diseases. In: Burgdorf WHC, Katz SI, eds. Dermatology progress and perspectives. Proceedings of the 18th World Congress of Dermat

23 Hovnanian A, Hilal L, Blanchet-Bardon C, et al. Prenatal diagnosis of recessive dystrophic epidermolysis bullosa by analysis of intragenic type VII collagen PvuII polymorphism. F Invest Dermatol 1993;100:515A.

24 Tamai Y, Zhang X, Christiano AM, Hovnanian A, Uitto J PCR-based detection of intragenic RFLPs in the human type VII collagen gene: applications to prenatal diagnosis of dystrophic epidermolysis bullosa. 7 Invest Dermatol 1993;101:482A.

25 Garcia DK, Sherman S, Leach RS, et al. CA repeat polymorphisms for h

26 NIH/CEPH collaborative mapping group A comprehensive genetic linkage map of the human genome. Science 1992; 258:67-84.

27 Eady RAJ. Transmission electron microscopy. In: Skerrow D, Skerrow CJ, eds. Methods in skin research. Chichester: John Wiley, 1985:1-36.

28 Leigh IM, Purkis PE, Bruckner-Tuderman L. LH7:2 monoclonal antibody detects type VII collagen in the basement membrane of ectodermally derived epithelia includin skin. Epithelia 1988;1:17-29.

29 Verrando P, Pisani A, Hsi BL, et al. Monoclonal antibody GB3, a new tool for the study of human basement membranes and hemidesmosomes. Exp Cell Res 1987;170: 116-28.

30 Lathrop MG, Lalouel JM. Easy calculation of lod scores and genetic risks on small computers. Am $\mathcal{f}$ Hum Genet 1984;36:460-5.

31 Christiano AM, Rosenbaum LM, Chung-Honet LC, et al. The large non-collagenous domain (NC-1) of type VII collagen is amino-terminal and chimeric. Homology to cartilage matrix protein, the type III domains of fibronectin and the A domains of von Willebrand factor. Hum Molec Genet 1992;1:475-81.

32 Greenspan DS, Byers MG, Eddy RL, Hoffman GG, Shows TB. Localization of the human collagen gene COL7A1 to $3 \mathrm{p} 21.3$ by fluorescence in situ hybridization. Cytogenet Cell Genet 1993;62:35-6. 